\title{
Second-generation antipsychotics and metabolic side-effects: Canadian population-based study
}

Lauren Hirsch, Scott B. Patten, Lauren Bresee, Nathalie Jette and Tamara Pringsheim

\section{Background}

Use of second-generation antipsychotics (SGA) has increased in recent years; however, their use and effect on metabolic outcomes has been poorly characterised in population-level studies.

\section{Aims}

This study aimed to determine the associations between SGA use and metabolic indicators in a general population.

\section{Method}

We used data from the Canadian Health Measures Survey, a cross-sectional survey of Canadian households. Participants were Canadians aged 3-79 years, living in one of the ten provinces. Several metabolic indicators were examined, including weight, body mass index, waist circumference, hypertension, diabetes and two definitions of metabolic syndrome.

\section{Results}

The proportion of Canadians taking an SGA tripled over the study period. SGA use was significantly associated with hypertension (odds ratio 1.94, 95\% $\mathrm{Cl} 1.07-3.55$ ) and abdominal obesity in adults, as defined by the National Cholesterol Education Program-Adult Treatment Panel III (odds ratio $2.62,95 \% \mathrm{Cl}$ 1.45-4.71).

\section{Conclusions}

Evidence of metabolic dysfunction with SGAs is seen in the Canadian population, along with a rapid increase in prevalence of use since 2007.

\section{Declaration of interest}

None.

\section{Keywords}

Second-generation antipsychotics; metabolic side-effects; population; epidemiology.

\section{Copyright and usage}

(c) The Royal College of Psychiatrists 2018. This is an Open Access article, distributed under the terms of the Creative Commons Attribution-NonCommercial-NoDerivatives licence (http://creativecommons.org/licenses/by-nc-nd/4.0/), which permits noncommercial re-use, distribution, and reproduction in any medium, provided the original work is unaltered and is properly cited. The written permission of Cambridge University Press must be obtained for commercial re-use or in order to create a derivative work.
Second-generation antipsychotics (SGAs) are a group of medications that include clozapine, olanzapine, risperidone, quetiapine, ziprasidone, paliperidone, lurasidone, asenapine and aripiprazole. SGAs were developed in the 1990s and are approved in Canada for the treatment of adolescents and adults with schizophrenia and bipolar disorder, and in adults as an adjunctive treatment for depression unresponsive to antidepressants (quetiapine and aripiprazole). In addition, SGAs are often prescribed off-label, for insomnia and generalised anxiety disorders in adults, ${ }^{1}$ as well as to children with aggressive behaviour and conduct disorders. ${ }^{2}$ The development of SGAs was met with high expectations, as they appeared to lack many of the adverse extrapyramidal side-effects associated with first-generation antipsychotics. ${ }^{3}$ However, in randomised controlled trials (RCTs), SGAs have been shown to be associated with adverse metabolic side-effects such as weight gain, dyslipidaemia, hyperglycaemia, hypertension and type 2 diabetes, leading to treatment discontinuation ${ }^{5}$ and severe long-term health consequences in many patients. ${ }^{6}$

Although RCTs have established a relationship between SGAs and metabolic dysfunction in clinical trial populations, research has been generally limited to short-term trials that explore incident cases, and therefore cannot account for other factors that influence prevalence in the population, such as disease severity and duration. The relationship between SGAs and metabolic side-effects is especially important because the underlying diseases that SGAs are used to treat carry risks of metabolic dysfunction as well. Several studies have shown that metabolic abnormalities and coronary disease are more prevalent in people with schizophrenia. ${ }^{7-9}$ Further, people with mental illnesses are significantly more likely to develop and die prematurely as a result of cardiovascular disease, regardless of antipsychotic treatment. ${ }^{10,11}$ A solid understanding of the population-level associations between SGAs and health can add to the understanding of the effect of these medications, an important consideration for both clinicians and patients in managing treatment. Here, we aimed to quantify the association between SGAs and metabolic dysfunction in the population, using a large and nationally representative sample.

\section{Method}

\section{Objectives}

This research aimed to address two objectives. The primary objective was to quantify the association between SGAs and evidence of metabolic dysfunction in the Canadian population. To assess this association, three separate cycles of the Canadian Health Measures Survey (CHMS), a cross-sectional Canadian population health survey, were examined. To understand the overall effect of these associations, an understanding of the frequency of SGA use in Canada is also necessary. Other studies have shown that SGA use has recently increased in Canada and as such, a second objective was to identify the number of Canadians taking SGAs and assess how the prevalence of use has changed over the three cycles of the CHMS.

\section{Data source and participants}

The CHMS is a cross-sectional survey of Canadians aged 3-79 years. ${ }^{12}$ Launched in 2007, the purpose of the CHMS is to directly collect nationally representative data to enable the study of 
disease, health status and emerging public health issues in the Canadian population. ${ }^{12}$ To produce a nationally representative sample, the CHMS sample is stratified by 11 age-gender groups, with approximately $500-600$ units per group. ${ }^{12}$ The nationwide sampling frame was stratified across five regions based on census data, and grouped with respect to provincial boundaries, health regions and population-density data. ${ }^{12}$ The first phase of CHMS data collection involved a household visit, where a Statistics Canada interviewer obtained information from selected respondents by computer-assisted personal interview. ${ }^{13}$ Content of the household visit questionnaires includes variables related to health status, nutrition and food, medication use, health behaviours, environmental factors and socioeconomic information. ${ }^{13}$ The mobile clinic portion of the CHMS involves screening, blood and urine collection, cardiorespiratory measurements, anthropomorphic measurements and muscular strength assessments. ${ }^{14}$ The survey does not include approximately $4 \%$ of the Canadian population, as persons living on reserves, in aboriginal settlements, in the three territories, members of the armed forces, institutionalised persons and residents of certain remote regions were not sampled. ${ }^{12}$ Detailed reports of the sampling strategy have been previously published. ${ }^{12}$

The first three cycles of the CHMS, covering the period 20072013, were used in this research. Prevalence estimates were obtained using all CHMS respondents aged 3-79 years, whereas only those aged 18 years and older were included in our analysis of metabolic dysfunction because of changing cut-off values for metabolic indicators over the life cycle. Permission to use the CHMS data was obtained through an application to Statistics Canada, and an ethics waiver was also obtained from the Conjoint Health Research Ethics Board at the University of Calgary, consistent with the standards of the Tri-Council Policy Statement 2 (2014). Furthermore, data was accessible only through the Statistics Canada Prairie Regional Data Centre, located at the main campus of the University of Calgary. Statistics Canada analysts vetted all research outputs gathered in the Prairie Regional Data Centre to ensure Statistics Canada research and confidentiality guidelines were upheld. Sample size restrictions laid out by Statistics Canada were followed in this analysis; some associations that were examined were not reportable under these guidelines.

\section{SGA status}

The Anatomical Therapeutic Chemical Classification System was used to code medication data in the CHMS (https://www.whocc. no/atc_ddd_index/). Metabolic dysfunction was assessed in all participants aged $>18$ years that took SGAs and those that did not. Prevalence estimates were obtained for individual SGAs when possible and for SGA use as a group. For analysis of metabolic outcomes, respondents taking multiple SGAs were not viewed differently than respondents taking only one SGA. Participants that took multiple SGAs could not be analysed separately from those that took one SGA because of sample size restrictions.

\section{Outcomes}

Several indicators of metabolic dysfunction were assessed, including weight, body mass index (BMI), waist circumference and systolic and diastolic blood pressure. Derived variables were created to group CHMS respondents based on their metabolic characteristics. Definitions for these variables can be found in Table 1. We also used two definitions of metabolic syndrome, outlined by the International Diabetes Federation (IDF) and the National Cholesterol Education Program-Adult Treatment panel III (NCEP-ATP III), to assess for metabolic dysfunction in CHMS respondents. These definitions can also be found in Table $1 .{ }^{15,16}$

\section{Analysis}

Logistic and linear regression models were used to compare respondents taking SGAs with those that did not, on all metabolic outcomes. An assessment of effect measure modification and confounding by age and gender was conducted by nested models. Effect measure modification was examined for statistical

\begin{tabular}{|c|c|}
\hline Variable & Definition \\
\hline Measured hypertension & $\begin{array}{l}\text { Systolic blood pressure } \geq 30 \mathrm{mmHg} \\
\quad \text { or diastolic blood pressure } \geq 85 \mathrm{mmHg}\end{array}$ \\
\hline $\begin{array}{l}\text { Measured hypertension or use of antihypertensive } \\
\text { medication }\end{array}$ & As above, or reporting use of an antihypertensive medication in the past month \\
\hline IDF abdominal obesity & $\begin{array}{l}\text { Waist circumference } \geq 94 \mathrm{~cm} \text { in males } \\
\qquad \text { or } \geq 80 \mathrm{~cm} \text { in females }\end{array}$ \\
\hline NCEP-ATP III abdominal obesity & $\begin{array}{l}\text { Waist circumference } \geq 102 \mathrm{~cm} \text { in males } \\
\text { or } \geq 89 \mathrm{~cm} \text { in females }\end{array}$ \\
\hline Overweight and obese BMI & $\mathrm{BMl} \geq 25 \mathrm{~kg} / \mathrm{m}^{2}$ \\
\hline Obese BMI & $\mathrm{BMl} \geq 30 \mathrm{~kg} / \mathrm{m}^{2}$ \\
\hline IDF metabolic syndrome & $\begin{array}{l}\text { Meets criteria for IDF metabolic syndrome: } \\
\text { - IDF abdominal obesity } \\
\text { - } \text { Triglycerides } \geq 170 \mathrm{mmol} / \mathrm{L} \\
\text { - } \text { High-density lipoprotein }<1.0 \mathrm{mmol} / \mathrm{L} \text { in } \mathrm{men} \text { or }<1.3 \mathrm{mmol} / \mathrm{L} \text { in women } \\
\text { - } \text { Blood pressure } 130 \mathrm{mmHg} \text { systolic or } \geq 85 \mathrm{mmHg} \text { diastolic } \\
\text { - } \text { Fasting glucose } \geq 5.6 \mathrm{mmol} / \mathrm{L} \\
\text { - } \text { Must have IDF abdominal obesity plus two out of four of the other criteria for a positive } \\
\text { diagnosis }\end{array}$ \\
\hline NCEP-ATP III metabolic syndrome & $\begin{array}{l}\text { Meets criteria for NCEP-ATP III metabolic syndrome: } \\
\text { - } \text { NIH abdominal obesity } \\
\text { - } \text { Triglycerides } \geq 170 \mathrm{mmol} / \mathrm{L} \\
\text { - } \text { High-density lipoprotein }<1.0 \mathrm{mmol} / \mathrm{L} \text { in } \mathrm{men} \text { or }<1.3 \mathrm{mmol} / \mathrm{L} \text { in women } \\
\text { - } \text { Blood pressure } 130 \mathrm{mmHg} \text { systolic or } \geq 85 \mathrm{mmHg} \text { diastolic } \\
\text { - } \text { Fasting glucose } \geq 5.6 \mathrm{mmol} / \mathrm{L} \\
\text { - } \text { Must have three out of the five criteria for a positive diagnosis }\end{array}$ \\
\hline
\end{tabular}


Table 2 Prevalence of second-generation antipsychotics (SGAS) and quetiapine use in each cycle of the Canadian Health Measures Survey

$\begin{array}{lcc}\text { Cycle } & \text { SGA use, \% (95\% Cl) } & \text { Quetiapine use, \% (95\% Cl) } \\ 1(2007-2009) & 0.42(0.27-0.58) & 0.20(0.08-0.32) \\ 2(2009-2011) & 1.23(0.51-1.94) & 0.79(0.22-1.36) \\ 3(2011-2013) & 1.71(0.93-2.50) & 0.97(0.36-1.56)\end{array}$

significance with a likelihood ratio test. Confounding was examined through manual backwards elimination of interaction terms. Interaction terms were removed from the model individually and a subjective assessment of any change in the association was performed to determine if individual variables acted as confounders in the model. A non-parametric sign test was performed to test the expected directionality of our associations. Sample estimates were calculated with survey weights provided by Statistics Canada to create population representative estimates. A bootstrap variance estimation procedure was used to adjust the variance and confidence intervals of our prevalence estimates to account for the complex clustered sampling design. STATA 13.1 (StataCorp LP, College Station, Texas) was used as the statistical software for all data analysis presented here. When $P$-values were obtained, an $a$ priori $\alpha$ significance level of 0.05 was used.

\section{Results}

\section{Trends in SGA use}

The estimated prevalence of all SGA use and the estimated prevalence of quetiapine use were determined for each cycle of the CHMS. To maintain survey respondent confidentiality, Statistics Canada requires minimum cell counts to be met when estimates are released to the public. Because of these requirements, separate prevalence estimates for other SGAs could not be published. The estimated percentage of Canadians taking any SGA or quetiapine during each cycle of the CHMS is displayed in Table 2 and Fig. 1. Both total SGA and quetiapine use increased over the three cycles of the CHMS; proportions of both approximately tripled from cycle one to cycle three.

The estimated proportions of total SGA use attributed to quetiapine, risperidone and other SGAs were calculated and are shown in Table 3 and Fig. 2. There were no significant differences in the estimated proportions of total SGA use attributed to quetiapine, risperidone or other SGAs when calculated separately for each cycle, therefore the separate cycle estimates were combined to increase precision. Based on the CHMS data, quetiapine use accounts for approximately half of all SGA use in Canada. Risperidone is the second most commonly used SGA in Canada, with approximately one-quarter of respondents who use SGAs reported as taking risperidone. Less than one-quarter of respondents taking SGAs in Canada use an SGA other than quetiapine or risperidone.

\section{Metabolic dysfunction}

SGA use was significantly associated with hypertension (as defined by measured hypertension or use of an antihypertensive medication) and the NCEP-ATP III definition of abdominal obesity in adults (Table 4). Other indicators of metabolic dysfunction (measured hypertension, IDF-defined abdominal obesity, overweight and obese BMI, obese BMI) and both definitions of metabolic syndrome (NCEP-ATP III and IDF) had estimated odds ratios $>1$, but the $95 \%$ confidence intervals crossed the null value of 1 . All eight of the associations examined in adult CHMS respondents have an estimated odds ratio of $>1$, leading to a significant sign test $(P=0.0039)$. This shows that, when taken in aggregate, indicators of metabolic dysfunction are associated with SGA use in adults.

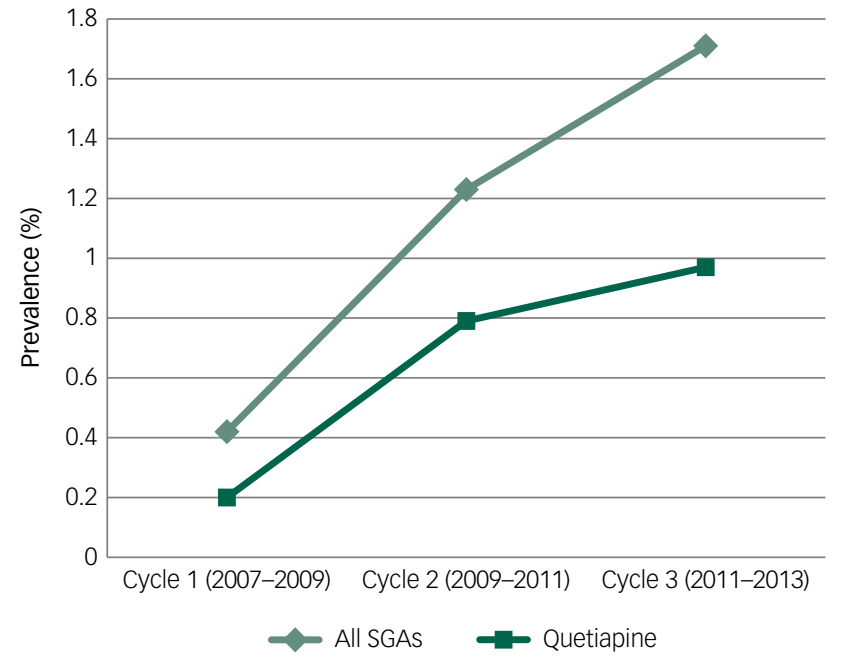

Fig. 1 Prevalence of second-generation antipsychotics (SGAs) and quetiapine use in each cycle of the Canadian Health Measures Survey.

\begin{tabular}{|c|c|}
\hline Medication & Proportion of total SGA use $(95 \% \mathrm{Cl})$ \\
\hline Quetiapine & $0.58(0.45-0.72)$ \\
\hline Risperidone & $0.25(0.12-0.38)$ \\
\hline Other SGAS & $0.16(0.08-0.23)$ \\
\hline
\end{tabular}

Age was not found to be an effect measure modifier or confounder. Some variables included gender in the coding, such as abdominal obesity, because different cut-off values were considered for males and females. For measures where this was not the case (measured hypertension, measured hypertension/use of an antihypertensive medication and both BMI variables), gender was considered in

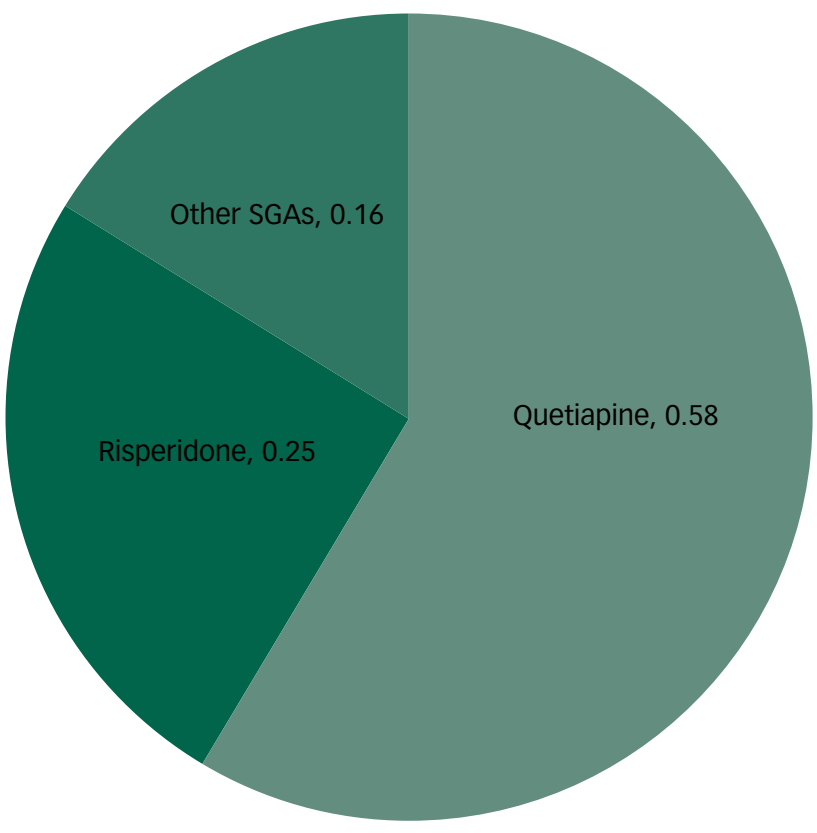

Fig. 2 Proportion of individuals taking quetiapine, risperidone or other second-generation antipsychotic (SGA). Please note the remaining 0.01 can be considered 'decimal dust'. 


\begin{tabular}{|c|c|c|c|c|}
\hline Variable & $\begin{array}{l}\text { Estimated odds ratio } \\
(95 \% \mathrm{Cl})\end{array}$ & $P$-value & $\begin{array}{l}\text { Gender-adjusted odds } \\
\text { ratio }(95 \% \mathrm{Cl})\end{array}$ & $P$-value \\
\hline Hypertension & $1.85(0.85-3.99)$ & 0.119 & $1.92(0.90-4.08)$ & 0.09 \\
\hline Measured hypertension or use of antihypertensive medication & $1.94(1.07-3.55)$ & $0.03^{\mathrm{a}}$ & $2.04(1.13-3.66)$ & $0.018^{\mathrm{a}}$ \\
\hline IDF abdominal obesity & $1.45(0.78-2.70)$ & 0.239 & NA & NA \\
\hline NCEP-ATP III abdominal obesity & $2.62(1.45-4.71)$ & $0.001^{a}$ & NA & NA \\
\hline Overweight and obese BMI & $1.3(0.71-2.38)$ & 0.398 & $1.4(0.79-2.48)$ & 0.253 \\
\hline Obese BMI & $1.71(0.91-3.20)$ & 0.092 & $1.72(0.92-3.21)$ & 0.088 \\
\hline IDF metabolic syndrome & $1.69(0.67-4.30)$ & 0.268 & NA & NA \\
\hline NCEP-ATP III metabolic syndrome & $2.15(0.84-5.46)$ & 0.107 & NA & NA \\
\hline
\end{tabular}

the model as a potential covariate. Gender was not found to be an effect measure modifier or confounder, but gender-adjusted odds ratios are still presented when possible. Odds ratios and $95 \%$ confidence intervals for indicators of metabolic dysfunction and both definitions of metabolic syndrome can be found in Table 4 .

Continuous variables were further examined by linear regression to calculate estimated mean differences between respondents taking SGAs and those not taking SGAs in the combined/adults file. All variables were examined in all adults, and in males and females separately. Estimated mean differences can be found in Table 5. When examined as continuous variables, those taking SGAs had significantly higher estimated waist circumference and higher estimated BMI; however, a significant difference in estimated BMI was not seen when stratified by gender. All other ratings were higher in respondents taking SGAs, but not significantly so. Estimated differences in systolic and diastolic blood pressure were clinically negligible, however, these ratings were not adjusted for antihypertensive medication use.

\section{Discussion}

This study was designed to investigate SGA use in the Canadian population. SGAs are a well-studied group of medications; however, much of the knowledge about SGAs is limited to clinical populations. This study contributed to the overall knowledge of these medications by expanding that information to the household population, an especially important consideration given the frequent off-label use of these medications.

Data from the CHMS confirmed and expanded on results from previous studies showing increasing SGA use in the Canadian population. ${ }^{1,17-20}$ This study is the first to confirm these results with data from a source other than a prescription drug database. The data presented here illustrate that the number of people taking SGAs is increasing, with an approximately threefold increase in the proportion of Canadians taking SGAs in general and the proportion of Canadians taking quetiapine between cycle one (2007-2009) and cycle three (2011-2013). This is consistent with the reported 300\% increase in quetiapine prescriptions dispensed in a similar time period (2005-2012). ${ }^{1}$ Furthermore, our reported quetiapine prevalence in cycle three $(0.97 \%, 95 \%$ CI $0.36-1.56 \%)$ is in line with findings from a provincial study in Alberta showing a quetiapine use prevalence of $1.3 \% .{ }^{21}$ Our reported prevalence estimates include children and adults, as separate proportions for the adult and child populations could not be released. However, based on previous studies that have examined SGA prescription rates for these age groups separately, it is thought that the increase in proportions is valid as an all ages measure, as use has been increasing in Canada for all age groups.

Studies have shown that the estimated prevalence of bipolar type 1 disorder and major depressive disorder have not changed in recent years in Canada. ${ }^{22-24}$ It is unlikely, then, that the increase in SGA use can be attributed to any increase in the prevalence of the underlying conditions. Therefore, the observed increase is most likely attributable to other factors, including the approval of quetiapine for the adjunctive treatment of major depressive disorder in 2009, increased off-label prescribing ${ }^{1,21}$ or a switch in preference to SGAs by clinicians and patients. The reason for this increase could not be directly studied in this data-set, nor could assumptions about off-label usage suggested by other studies be examined by dosage information. Some studies ${ }^{25-27}$ have examined factors that influence providers' choice in SGA prescribing patterns, but have found inconsistent results regarding the role of patient characteristics on medication choice. In summary, the increase in SGA use in the Canadian population has been confirmed by this study, yet SGA prescribing patterns in general are still inadequately described.

\begin{tabular}{|c|c|c|}
\hline Variable (units) & Estimated mean difference $(95 \% \mathrm{Cl})$ & $P$-value \\
\hline Systolic blood pressure (mmHg) & $1.99(-1.78$ to 5.86$)$ & 0.313 \\
\hline Female & $3.73(-1.81$ to 9.28$)$ & 0.187 \\
\hline Male & $0.43(-4.08$ to 4.93$)$ & 0.853 \\
\hline Diastolic blood pressure (mmHg) & $1.35(-2.00$ to 4.71$)$ & 0.427 \\
\hline Female & $0.49(-2.80$ to 3.78$)$ & 0.771 \\
\hline Male & $3.98(-0.88$ to 8.84$)$ & 0.108 \\
\hline Waist circumference $(\mathrm{cm})$ & $7.78(2.20-13.36)$ & $0.006^{a}$ \\
\hline Female & $9.44(2.41-16.47)$ & $0.008^{a}$ \\
\hline Male & $7.26(-0.73$ to 15.25$)$ & 0.075 \\
\hline Body mass index $\left(\mathrm{kg} / \mathrm{m}^{2}\right)$ & $2.06(0.13-3.97)$ & $0.036^{a}$ \\
\hline Female & $2.74(-0.6$ to 5.54$)$ & 0.055 \\
\hline Male & $1.14(-1.30$ to 3.58$)$ & 0.361 \\
\hline
\end{tabular}


We found the prevalence of hypertension, diagnosed by direct measurement plus use of an antihypertensive medication, and abdominal obesity defined by the NCEP-ATP III criteria were significantly higher in respondents taking SGAs than those that did not. The prevalence of abdominal obesity defined by the IDF criteria, obese BMI and overweight BMI were higher, but not statistically significantly higher, in respondents taking SGAs than those that did not. The prevalence of obese BMI and overweight/obese BMI in adult respondents that did not take SGAs in all three cycles of the CHMS are in line with other studies reporting on increasing and elevated weight in Canadians. We found an estimated 61\% (95\% CI 58.4-63.5\%) of adult respondents that did not take SGAs had a BMI $\geq 25$ and an estimated $25.4 \%$ (95\% CI 23.2-27.6\%) had a $\mathrm{BMI} \geq 30$; previous reports of all adult Canadians have shown the prevalence of BMI $\geq 25$ to be approximately $45 \%$ and BMI $\geq 30$ to be approximately $23 \%{ }^{28}$ These results show that increased weight, as demonstrated by elevated BMI, is a problem for the general Canadian population regardless of SGA use. Furthermore, the IDF definition of abdominal obesity uses relatively low cut-off values, and thus nearly $60 \%$ of Canadians have abdominal obesity based on these guidelines. On the other hand, the NCEP-ATP III criteria for abdominal obesity are higher, thus only very abdominally obese persons would qualify based on these criteria. As a significantly higher proportion of respondents taking SGAs fall into this category, it is possible that SGA use is associated with extremely elevated abdominal obesity, as opposed to the more moderate abdominal obesity reflected in the IDF criteria.

The same trend is seen in the associations between SGA use and metabolic syndrome. All odds ratios are elevated in the SGA group, with a significant sign test indicating that SGA use is generally associated with a trend toward metabolic dysfunction. These results confirm findings from previous studies in sub-populations and expand their generalisability to the household population. In our study, hypertension and abdominal obesity as defined by the NCEP-ATP III are most strongly associated with SGA use in the general population, again indicating that extreme abdominal obesity is more prevalent in respondents taking SGAs than in the general population. As abdominal obesity has been the metabolic indicator most closely linked with increased risk of cardiovascular disease, these results are especially troubling. Significant results in other indicators were likely not found because of limited sample size and power. Large variance in the sample and correspondingly wide confidence intervals can be seen; we hypothesise that with a larger sample size, these associations would also be statistically significant.

These findings are also confirmed in the linear regression analysis. BMI was significantly different in respondents taking SGAs, although when stratified by gender, the difference became insignificant. Females who were taking SGAs were shown to have a mean waist circumference of 9.44 (95\% CI 2.41-16.47) cm greater than their counterparts who did not take SGAs. Males who were taking SGAs also had a larger mean waist circumference, although it was not statistically significantly different at 7.26 (95\% CI -0.73 to $15.25) \mathrm{cm}$. When examined as a continuous variable, both systolic and diastolic blood pressure were non-significantly higher in respondents taking SGAs than those that did not. This analysis could not be adjusted for use of an antihypertensive medication because of sample size restrictions; it is likely that such an adjustment would alter this result.

\section{Limitations}

Although the literature has established, and we have confirmed, that the use of SGAs has rapidly increased in recent years, the overall prevalence of SGA use remains low. In the latest cycle (2012-2013) of the CHMS, we estimated that the per cent of
Canadians taking any SGA was 0.93-2.50. Even with a large population-based survey, this left a relatively small number of people taking SGAs in which to examine the associations we aimed to quantify in this study. The small sample size, combined with a complex sampling design and Statistics Canada sample size release requirements, led to some important considerations in our analysis. For example, those that took multiple SGAs could not be separately studied from those that took a single SGA. SGA use rates could also only be separately calculated for risperidone and quetiapine, and trends for use of other SGAs such as clozapine and olanzapine are not reported. The small sample size is also an important factor to consider when examining the reported 95\% confidence intervals, which were often wide and therefore imprecise. Given these limitations, increasing the sample size in future studies would be helpful to obtain more precise estimates and allow for a successful and reliable use of the bootstrap variance estimation procedure.

Potential confounders that we were unable to consider could also affect our results. Although we adjusted some of our estimates for gender, we were not always able to do so because of sample size considerations. Other potential confounders we could not include in our analysis for the same reason, such as age, underlying diagnosis and socioeconomic variables, could also bias our results. Furthermore, a high percentage of people taking SGAs in our study reported having a mood disorder. Other treatments for mood disorders, such as selective serotonin reuptake inhibitors, have been shown to cause weight gain. ${ }^{29}$ It was not possible to remove participants on one of these other medications from our analysis because of the sample size consideration; a re-analysis that takes this potential confounder into consideration would be suggested if future studies have sufficient sample size to do so. However, we have been able to show that that associations between SGA use and metabolic dysfunction seen in RCTs have carried over into the general household population. ${ }^{29,30}$ Because of the limitations discussed here, the results of this study should be interpreted in context and evaluated within the broader scope of the literature pertaining to SGAs and metabolic side-effects.

In conclusion, these findings, coupled with the continued increase in SGA use in Canada, indicate that SGAs are having a significant effect in the Canadian population. Knowing that the association between SGAs and metabolic dysfunction has been established by a variety of methodologies and has been studied both in clinical and household populations, it is imperative that clinicians are educated and seriously undertake metabolic monitoring of patients taking SGAs. Furthermore, as previous research ${ }^{31,32}$ has shown that rates of metabolic monitoring in patients with psychiatric disorders who are taking SGAs remain low despite published guidelines, strategies to increase adherence to these recommendations should be developed and implemented.

Lauren Hirsch, MSc, Medical Student, Department of Community Health Sciences, Hotchkiss Brain Institute and O'Brien Institute of Public Health, University of Calgary, Canada; Scott B. Patten, MD, Professor, Department of Community Health Sciences, Hotchkiss Brain Institute, Department of Clinical Neurosciences, and O'Brien Institute of Public Health, University of Calgary, Canada; Lauren Bresee, PhD, Adjunct Assistant Professor, Department of Community Health Sciences and O'Brien Institute of Public Health, University of Calgary, Canada; Nathalie Jette, MD, Professor, Department of Community Health Sciences, Hotchkiss Brain Institute, Department of Clinical Neurosciences, and O'Brien Institute of Public Health, University of Calgary, Canada; Tamara Pringsheim, MD, Associate Professor, Department of Community Health Sciences, Hotchkiss Brain Institute and Department of Clinical Neurosciences, University of Calgary, Canada

Correspondence: Tamara Pringsheim, Mathison Centre for Mental Health Research and Education, 3280 Hospital Drive NW, Calgary, Alberta T2N 4Z6, Canada. Email: tmprings@ucalgary.ca

First received 5 May 2017, final revision 11 Apr 2018, accepted 19 May 2018 


\section{References}

1 Pringsheim T, Gardner D. Dispensed prescriptions for quetiapine and other second generation antipsychotics in Canada from 2005 to 2012: a descriptive study. CMAJ Open 2014; 2(4): E225-32.

2 Pringsheim T, Lam D, Patten SB. The pharmacoepidemiology of antipsychotic medications for Canadian children and adolescents, 2005-2009. J Child Adolesc Psychopharmacol 2011; 21(6): 1-8.

3 Divac N, Prostran M, Jakovcevski I, Cerovac N. Second generation antipsychotics and extrapyramidal adverse events. Biomed Res Int 2014; 2014: 656370.

4 Chaplain S, Taylor M. Drug points: second generation antipsychotics. Prescriber 2014; 14(21): 12-21.

5 McEvoy J, Meyer J, Goff D, Nasrallah HA, Davis S, Sullivan L, et al. Prevalence of the metabolic syndrome in patients with schizophrenia: baseline results from the Clinical Antipsychotic Trials of Intervention Effectiveness (CATIE) Schizophrenia trial and comparison with national estimates from NHANES III. Schizophr Res 2005; 80(1): 19-32.

6 Kurzthaler I, Fleischhacker WW. The clinical implications of weight gain in schizophrenia. J Clin Psychiatry 2001; 62(suppl 7): 32-7.

7 Hagg S, Lindblom Y, Mjorndal T, Adolfsoon R. High prevalence of the metabolic syndrome among a Swedish cohort of patients with schizophrenia. Int Clin Psychopharmacol 2006; 21: 93-8.

8 Brown S. Excess mortality of schizophrenia. A meta-analysis. Br J Psychiatry 1997; 171: 502-8.

9 Mortensen $\mathrm{P}$, Juel K. Mortality and causes of death in first admitted schizophrenic patients. Br J Psychiatry 1993; 163: 183-9.

10 Harris E, Barraclough B. Excess mortality of mental disorder. Br J Psychiatry 1998: 173: 11-53.

11 Laursen $\mathrm{T}$, Munk-Olsen $\mathrm{T}$, Vestergaard $\mathrm{M}$. Life expectancy and cardiovascula mortality in persons with schizophrenia. Curr Opin Psychiatry 2012; 25(2): 83-8.

12 Statistics Canada. Canadian Health Measures Survey 2016-2017. Statistics Canada, 2017 (http://www23.statcan.gc.ca/imdb/p2SV.pl?Function=getSurvey \&SDDS=5071)

13 Tremblay M, Wolfson M, Gorber S. Canadian Health Measures Survey: rationale, background and overview. Health Rep 2007: 18(suppl): 6-20.

14 Bryan S, St-Denis M, Wojtas D. Canadian Health Measures Survey: clinic operations and logistics. Health Rep 2007; 82(suppl): 52-70.

15 NCEP-ATP III. Third report of the National Cholesterol Education Program (NCEP) expert panel on detection, evaluation, and treatment of high blood cholesterol in adults. (Adult Treatment Panel III). Final Report. Circulation 2002; 106 3143-421.

16 Alberti K, Zimmet $P$, Shaw J. Metabolic syndrome-a new world-wide definition. A consensus statement from the international diabetes federation. Diabet Med 2006; 23: 469-80.
17 Alessi-Severini S, Biscontri R, Collins D, Kozyrskyj A, Sareen J, Enns M. Utilization and costs of antipsychotic agents: a Canadian population based study 1996-2006. Psychiatr Serv 2008; 59(5): 547-53.

18 Alessi-Severini S, Biscontri R, Collins D, Sareen J, Enns M. Ten years of antipsychotic prescribing to children: a Canadian population-based study. Can J Psychiatry 2012; 57(1): 52-8.

19 Dewa C, Remington G, Herrmann N, Fearnley J, Goering P. How much are atypical antipsychoitc agents being used, and do they reach the populations who need them? A Canadian experience. Clin Ther 2002; 24(9): 1466-76.

20 Murphy A, Gardner DM, Cooke C, Kisely S, Hughes J, Kutcher S. Prescribing trends of antipsychotics in youth receiving income assistance: results from a retrospective population database study. BMC Psychiatry 2013; 13(198): 1-13.

21 Duncan D, Cooke L, Symonds C, Gardner DM, Pringsheim T. Quetiapine use in adults in the community: a population-based study in Alberta, Canada. BMJ Open 2016; 6: 1-7.

22 Patten S, Williams J, Lavorato D, Fiest K, Bulloch A, Wang J. The prevalence of major depression is not changing. Can J Psychiatry 2015; 60(1): 31-4.

23 Schaffer A, Cairney J, Cheung A, Veldhuizen S, Levitt A. Community survey of bipolar disorder in Canada: lifetime prevalence and illness characteristics. Can J Psychiatry 2006; 51(1): 9-16.

24 McDonald K, Bulloch A, Duffy A, Bresee L, Williams J, Lavorato D, et al. Prevalence of bipolar I and II disorder in Canada. Can J Psychiatry 2015; 60 (3): 151-6

25 Herbeck D, West J, Ruditis I, Duffy F, Fitek D, Bell C, et al. Variations in use of second-generation antipsychotic medication by race among adult psychiatric patients. Psychiatr Serv 2004; 55(6): 677-84.

26 Opolka J, Rascati K, Brown C, Gibson P. Ethnicity and prescription patterns for haloperidol, risperidone, and olanzapine. Psychiatr Serv 2004; 55(2): 151-6.

27 Connolly A, Taylor D. Ethnicity and quality of antipsychotic prescribing among in-patients in south London. Br J Psychiatry 2008; 193(2): 161-2.

28 Public Health Agency of Canada and Canadian Institute for Health Information. Obesity in Canada. Public Health Agency of Canada and Canadian Institute for Health Information, 2011 (https://www.canada.ca/content/dam/phac-aspc/ migration/phac-aspc/hp-ps/hl-mvs/oic-oac/assets/pdf/oic-oac-eng.pdf).

29 Aronne L, Segal K. Weight gain in the treatment of mood disorders. J Clin Psychiatry 2003; 64(suppl 8): 22-9.

30 Printz D, Clark J, Stricks L, Malaspina D. Weight gain in bipolar disorder: causes and treatments. Primary Psychiatry 2003; 10(11): 29-36.

31 Haupt D, Rosenblatt L, Kim E, Baker R, Whitehead R, Newcomer J. Prevalence and predictors of lipid and glucose monitoring in commercially insured patients treated with second-generation antipsychotic agents. Am J Psychiatry 2009; 166(3): 345-53.

32 Morrato $\mathrm{E}$, Druss $\mathrm{B}$, Hartung $\mathrm{D}$, Valuck $\mathrm{R}$, Allen $\mathrm{R}$, Campagna $\mathrm{E}$, et al Metabolic testing rates in 3 state Medicaid programs after FDA warnings and ADA/APA recommendations for second-generation antipsychotic drugs. Arch Gen Psychiatry 2010; 67(1): 17-24. 